$2008 ; 26: 545-8$.

4. Cheung HS, Ryan LM, Kozin F, et al. Synovial origins of Rice bodies in joint fluid. Arthritis Rheum 1980;23:726.

5. Nagasawa H, Okada K, Senma S, et al. Tenosynovitis with rice body formation in a non-tuberculosis patient: a case report. Ups J Med Sci 2009;114:184-8.

\section{Foreign-Body Granuloma after Metacarpal Fracture Treatment with Absorbable Implants}

Jung-Sik Choi, Jung-Ho Lee, Sue-Min Kim, Young-Jin Kim, Young-Joon Jun

Department of Plastic and Reconstructive Surgery, Bucheon St. Mary's Hospital, College of Medicine, The Catholic University of Korea, Seoul, Korea

Correspondence: Young-Joon Jun

Department of Plastic and Reconstructive Surgery, Bucheon St. Mary's

Hospital, College of Medicine, The Catholic University of Korea,

327 Sosa-ro, Wonmi-gu, Bucheon 420-717, Korea

Tel: +82-32-340-7062, Fax: +82-32-340-7062

E-mail: joony@catholic.ac.kr

No potential conflict of interest relevant to this article was reported.

Received: 6 Mar 2015 • Revised: 10 Apr 2015 • Accepted: 24 Apr 2015 pISSN: 2234-6163 • elSSN: 2234-6171

http://dx.doi.org/10.5999/aps.2015.42.4.505 • Arch Plast Surg 2015;42:505-507 Copyright (C) 2015 The Korean Society of Plastic and Reconstructive Surgeons This is an Open Access article distributed under the terms of the Creative Commons This is an Open Access article distributed under the terms of the Creative Commons
Attribution Non-Commercial License (http://creativecommons.org/licenses/by-nc/3.0/) Attribution Non-Commercial License (http://creativecommons.org/licenses/by-nc/3.o/
which permits unrestricted non-commercial use, distribution, and reproduction in any medium, provided the original work is properly cited.

The treatment of unstable fractures or complex injuries of the hand frequently requires the implementation of rigid internal fixation.

Traditionally, metallic implants have been used to achieve stability. However, the complication rates of metallic implants are high, with major complications reported in $36 \%$ of the patients considered in a series [1]. These complications included nonunion, delayed union, stiffness, plate palpation, infection, and tendon rupture. Therefore, bioabsorbable implants have been introduced to reduce these problems. The firstgeneration bioabsorbable implants showed a high complication rate due to weak mechanical properties and rapid degradation. This led to the development of stronger devices with improved durability. However, recently developed implants have raised concerns

about late-occurring adverse reactions such as foreign body reactions. Herein, a case of foreign body granuloma after the use of an absorbable implant will be presented with a brief literature review.

A 30-year-old male visited Bucheon St. Mary's hospital with a swelling on his left hand after a slipand-fall injury. He was diagnosed with a left fifth metacarpal bone fracture by hand computed tomography (CT) and X-rays (Fig. 1). The first operation was performed 8 days after the injury, and open reduction was performed. To stabilize the fracture segments, a bioabsorbable plate and screws (Linvatec Biomaterials Ltd., Tampere, Finland) were used for internal fixation. Although the 1-year followup was uneventful, the patient visited us with swelling on the previous operation site. Physical exam showed just the swelling of the soft tissue of the operation site without any fluctuation, heat, or erythema. We recommended further evaluation such as an imaging study, but the patient refused to undergo it. Therefore, we decided to observe the patient without administering any medication because there was no evidence of infection. Four months later, the patient visited us again because of another trauma at the same site. Physical examination, CT, and X-rays were conducted, and the patient was diagnosed with a refracture of the fifth metacarpal bone with increased soft tissue swelling as compared to when we first noticed it 4 months previously (Figs. 2,3 ). We

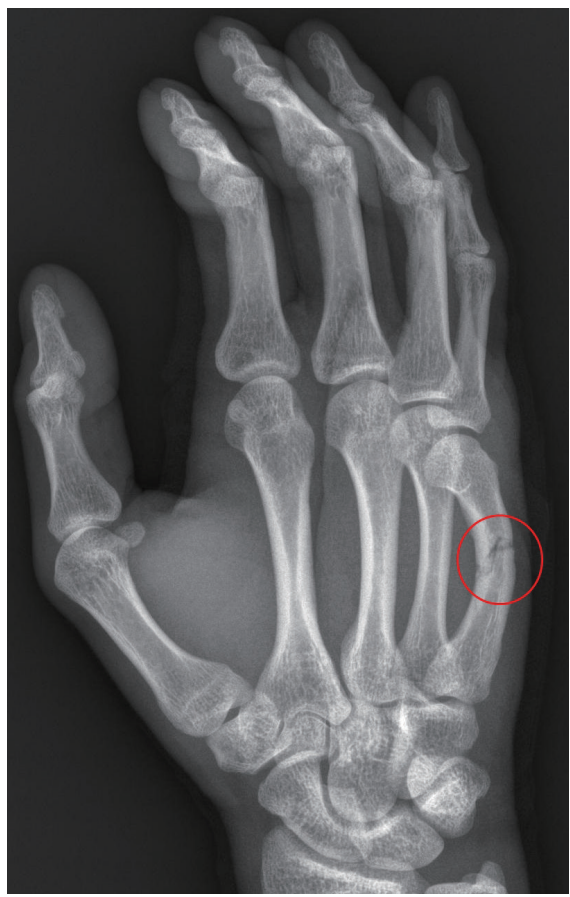

Fig. 1.

Preoperative X-ray of the first fracture event. The $X$-ray shows the fracture of the fifth metacarpal bone shaft of the left hand (red circle). 
decided to perform a second operation for the reduction of bone and exploration of soft tissue swelling. Under general anesthesia, an incision was made on the previous operation scar, and a mass was found in the subperiosteal layer. The mass was located just above the screw holes; it measured $2 \mathrm{~cm} \times 1 \mathrm{~cm}$ and was relatively well demarcated (Fig. 4). We excised the mass and used a metallic plate for rigid fixation. The tissue biopsy for the mass showed foreign body-type multinucleated giant cells suggestive of foreign body granuloma (Fig. 5). A 6-month follow-up from the second operation demonstrated a well-healing surgical incision with no erythema or swelling and no associated signs of infection.

The use of bioabsorbable implants has increased recently because of their advantages. They may lead to less implant morbidity and subsequent stiffness and do not require hardware removal surgery. Further, they are radiolucent and limit stress shielding, and they incrementally transfer the load to healing fractures.

On the other hand, their disadvantages include poor strength compared with metallic implants [2], rapid loss of initial strength, and relatively high refracture rates [3]. Further, they are prone to inducing foreign body reactions [4]. Moreover, there are few studies on the long-term effects of bioabsorbable implants on the treatment of metacarpal fractures. In one study [5], 4 of 9 patients left hand (red circle) who were treated with bioabsorbable implants for metacarpal fractures required a second operation because of a foreign body reaction. However, all of

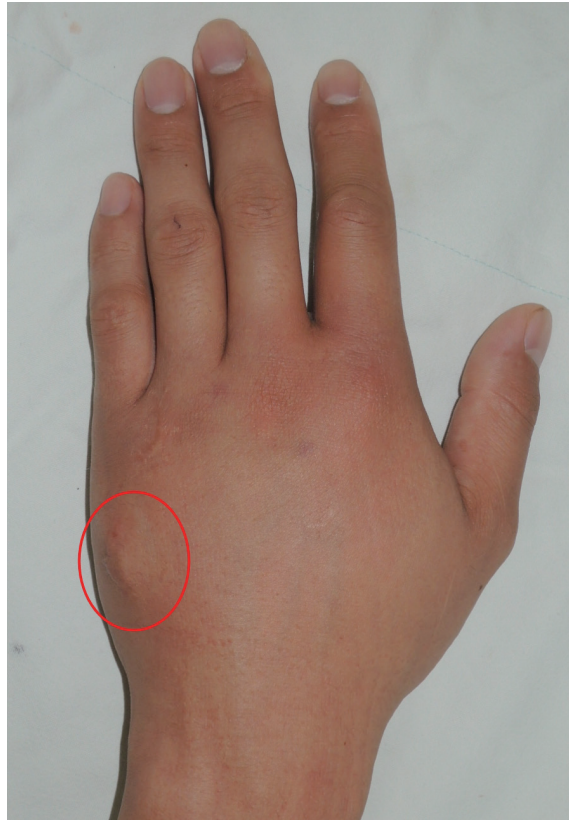

Fig. 3.

Preoperative clinical photo of the second fracture event. Soft tissue swelling can be seen without signs of infection (red circle).

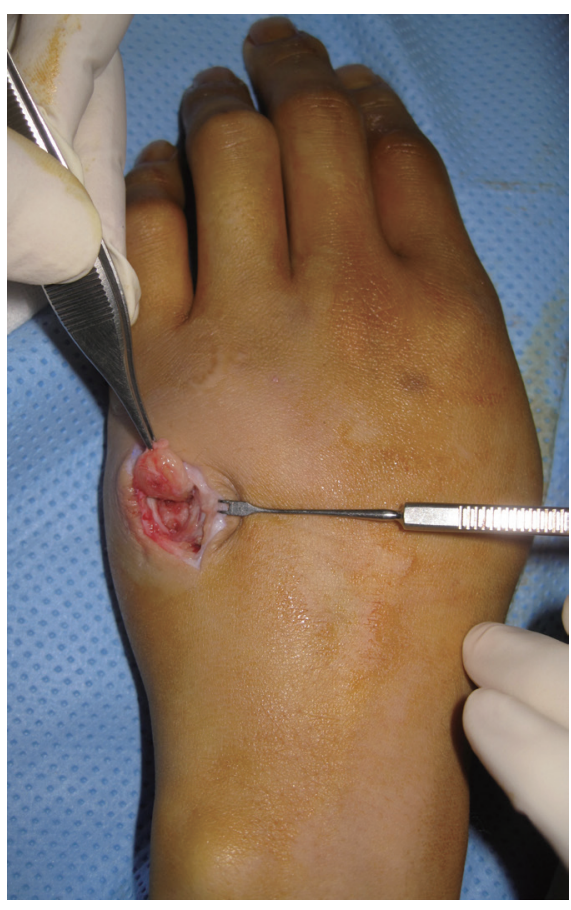

Fig. 4 .

Intraoperative clinical photo. The mass is located just above the screw holes. 


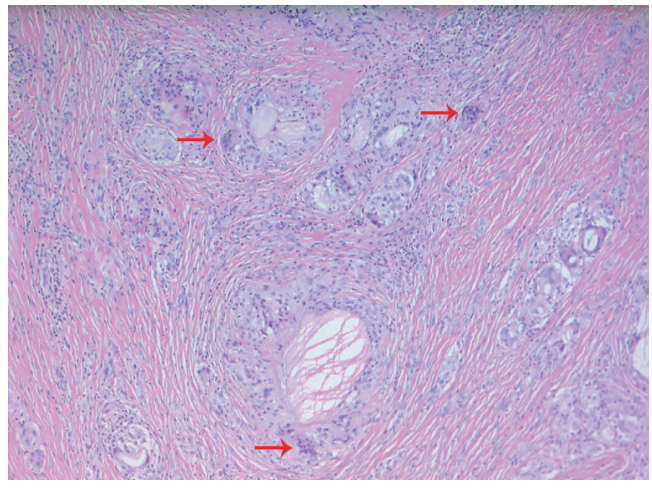

Fig. 5.

The histologic examination shows multinucleated giant cells (red arrows) suggestive of foreign body granuloma $\left(H \& E_{1} \times 100\right)$.

them just had fluid accumulation and no foreign body granuloma. This rarity of the foreign body granuloma formation makes our case worthy of report.

In conclusion, although bioabsorbable implants have many advantages, we suggest paying considerable attention to their disadvantages such as their low strength and tendency to cause foreign body reactions. Moreover, hands require the ability to perform a large number of motions and need to have more extensive weight-bearing features than other body sites; therefore, bioabsorbable implants might not be appropriate for use in the treatment of hand fractures.

In conclusion, we suggest that a foreign body granuloma ought to be considered in the differential diagnosis of any mass occurring after the use of bioabsorbable implants in the treatment of metacarpal fractures.

\section{References}

1. Page SM, Stern PJ. Complications and range of motion following plate fixation of metacarpal and phalangeal fractures. J Hand Surg Am 1998;23:827-32.

2. Buijs GJ, van der Houwen EB, Stegenga B, et al. Mechanical strength and stiffness of biodegradable and titanium osteofixation systems. J Oral Maxillofac Surg 2007;65:2148-58.

3. Waris E, Ashammakhi N, Happonen H, et al. Bioabsorbable miniplating versus metallic fixation for metacarpal fractures. Clin Orthop Relat Res 2003; (410):310-9.

4. Bergsma EJ, Rozema FR, Bos RR, et al. Foreign body reactions to resorbable poly(L-lactide) bone plates and screws used for the fixation of unstable zygomatic

fractures. J Oral Maxillofac Surg 1993;51:666-70.

5. Givissis PK, Stavridis SI, Papagelopoulos PJ, et al.

Delayed foreign-body reaction to absorbable implants in metacarpal fracture treatment. Clin Orthop Relat Res 2010;468:3377-83.

\section{Spontaneous Iliopsoas Hematoma: A Rare Complication of Anticoagulant Use}

\author{
Sang Wha Kim ${ }^{1}$, Dong Hwi Kim², Sung-No Jung ${ }^{2}$ \\ ${ }^{1}$ Department of Plastic and Reconstructive Surgery, Seoul \\ National University Hospital, Seoul National University College \\ of Medicine, Seoul; ${ }^{2}$ Department of Plastic and Reconstructive \\ Surgery, Uijeongbu St. Mary's Hospital, College of Medicine, \\ The Catholic University of Korea, Seoul, Korea
}

\section{Correspondence: Sung-No Jung}

Department of Plastic and Reconstructive Surgery, Uijeongbu St. Mary's Hospital, College of Medicine, The Catholic University of Korea, 271 Chenbo-ro, Uijeongbu 480-717, Korea

Tel: +82-31-820-3576, Fax: +82-31-847-0301

E-mail: jsn7190@catholic.ac.kr

No potential conflict of interest relevant to this article was reported.

Received: 17 Mar 2015 • Revised: 13 May 2015 • Accepted: 18 May 2015 pISSN: 2234-6163・ elSSN: 2234-6171

http://dx.doi.org/10.5999/aps.2015.42.4.507 • Arch Plast Surg 2015;42:507-510

Copyright (C) 2015 The Korean Society of Plastic and Reconstructive Surgeons

This is an Open Access article distributed under the terms of the Creative Commons

Attribution Non-Commercial License (http://creativecommons.org/licenses/by-nc/3.0/ which permits unrestricted non-commercial use, distribution, and reproduction in any medium, provided the original work is properly cited.

Hemorrhage occurs in $4 \%$ of patients receiving anticoagulant therapy $[1,2]$. Most hemorrhages are located in intracranial and retroperitoneal lesions. In this report, we describe a case of iliopsoas hematoma in a patient treated by heparin salvage after finger replantation, which was treated conservatively.

A 53-year-old male patient suffered a crushing injury of the third finger. On physical examination, volar oblique amputation in zone I was observed (Fig. 1). The initial laboratory examination showed hemoglobin levels, white blood cell count, and activated partial thromboplastic time (aPTT) within normal ranges with stable vital signs. Emergency replantation was performed with anastomosis of one artery and one vein (Fig. 2). Postoperatively, 5,000 IU of heparin was continually administered intravenously every 24 hours. Five days after surgery, 